\section{Review: percutaneous coronary angioplasty is associated with less angina but more coronary artery bypass grafting in patients with non-acute coronary artery disease than is medical treatment}

\author{
Bucher HC, Hengstler P, Schindler C, et al. Percutaneous transluminal coronary angioplasty versus medical treatment for \\ non-acute coronary heart disease: meta-analysis of randomised controlled trials. BMJ 2000 Jul 8;321:73-7.
}

Source of funding: no external funding:

For correspondence: Dr H Bucher, Medizinische Universitäts-Poliklinik, Kantonsspital Basel, CH-4031 Basel, Switzerland.

\section{Data sources}

Studies were identified by searching Medline, EMBASE/ Excerpta Medica, the Cochrane Library, and PASCAL for 1979 to 1998 with the terms transluminal percutaneous coronary angioplasty, cardiovascular agents, coronary disease, and random (with various endings). Bibliographies of review articles and studies were scanned.

\section{Study selection}

Randomised controlled trials were selected if PTCA was compared with medical care and if the patients had non-acute $\mathrm{CAD}$ and had had no acute $\mathrm{MI}$ in the previous week.

\section{Data extraction}

Data were extracted independently and in duplicate on study quality, clinical and angiographic inclusion criteria, number of vessels and proportion with successful dilation, treatment and related complications, length of follow up, comorbid conditions, mean ejection fraction, and outcomes (angina at the end of the study, MI, mortality, and need for repeat angioplasty or coronary artery bypass grafting $[\mathrm{CABG}])$.

\section{Main results}

429 trials were assessed, and 6 met the inclusion criteria. 953 patients were in the PTCA groups, and 951 were in the medical care groups. 3 studies included patients with multivessel disease or previous MI. Data were pooled by using a random effects model. Fewer patients in the PTCA groups had angina at the end of the study than did patients in the medical care groups; more patients in the PTCA groups needed CABG (table). The groups did not differ for rates of fatal or non-fatal MI (pooled relative risk [RR] $1.42,95 \%$ CI 0.90 to 2.25 ), mortality (RR 1.32 , CI 0.65 to 2.70), or need for repeated PTCA (RR 1.29, CI 0.71 to 3.36). However, few deaths (15 in the PTCA groups $v 11$ in the medical care groups) or MIs (41 in the PTCA groups $v 29$ in the medical care groups) occurred.

\section{Conclusion}

Percutaneous coronary angioplasty was associated with a lower rate of angina and a higher rate of coronary artery bypass grafting in patients with non-acute coronary artery disease.
Percutaneous coronary angioplasty (PTCA) v medical care for non acute coronary artery disease*

\begin{tabular}{|c|c|c|c|c|}
\hline \multirow[b]{2}{*}{ Outcomes at 6 to 57 months } & \multicolumn{2}{|c|}{ Weighted event rates } & \multirow[b]{2}{*}{$\operatorname{RRR}(95 \% \mathrm{CI})$} & \multirow[b]{2}{*}{ NNT (Cl) } \\
\hline & PTCA & Medical care & & \\
\hline \multirow[t]{2}{*}{ Angina at the end of study } & $53 \%$ & $70 \%$ & $30 \%(2$ to 50$)$ & 6 (3 to 637$)$ \\
\hline & & & RRI (CI) & NNH (Cl) \\
\hline Coronary artery bypass grafting & $7.6 \%$ & $4.1 \%$ & $59 \%$ (9 to 132$)$ & 29 (19 to 66$)$ \\
\hline
\end{tabular}

*Abbreviations defined in glossary; NNT, NNH, and their Cls calculated from data in article.

\section{COMMENTARY}

Each year approximately 1 million PTCAs are done worldwide. It is amazing that only 1904 patients have been randomly assigned in trials that compare PTCA with medical care. None of the 6 trials evaluated the benefit of optimal PTCA (current equipment, stents, clopidogrel, and platelet glycoprotein IIb/IIIa antagonists) added to optimal medical treatment (aspirin, $\beta$ blockers, statins, angiotensin converting enzyme inhibitors, diet, exercise, weight control, smoking cessation, and attainment of target goals for glucose and cholesterol concentrations and blood pressure).

The meta-analysis by Bucher et al might better be described as a pooled analysis because of the large differences in clinical and angiographic variables among the studies and the different durations of follow up. The reduction in the rate of angina with PTCA is underestimated because 3 of the trials enrolled patients without angina. The higher rate of CABG with PTCA is overestimated because revascularisation was encouraged in the PTCA group and discouraged in the medical group until the end of the trials when some patients crossed over to revascularisation. Other potential outcomes favoring PTCA, such as the reduction in the need for medication and increase in exercise time until symptoms appear, were not analysed because of inconsistent reporting in some of the trials, 1 of which has yet to be published.

Many patients in these trials did not meet American College of Cardiology-American Heart Association guidelines for PTCA, which include unsuccessful symptom control with medical treatment, significant proximal left anterior descending artery disease, or a moderate area of ischaemic myocardium on stress testing. Such patients are now being enrolled in the 3300 patient Clinical Outcomes Utilizing Revascularization and Aggressive Drug Evaluation (COURAGE) trial. ${ }^{1}$ Patients are receiving maximal medical treatment, with half also receiving optimal PTCA treatment. The hypothesis is that PTCA will reduce the primary end point of death or MI at 3 years. Until the results are announced, PTCA remains an excellent treatment option in appropriate stable patients for relieving angina and improving quality of life.

Eric R Bates, MD University of Michigan Ann Arbor, Michigan, USA

1 Blumenthal RS, Cohn G, Schulman SP. Medical therapy versus coronary angioplasty in stable coronary artery disease: a critical review of the literature. $J$ Am Coll Cardiol 2000;36:668-73. 